\title{
AS MULTIFACES COMUNICACIONAIS COM OS AUTISTAS NO AMBIENTE ORGANIZACIONAL
}

\author{
Marilani Soares Vanalli, Magna Rogéria dos Santos Sanches \\ Universidade do Oeste Paulista - UNOESTE, Administração, Presidente Prudente, São Paulo. E-mail: \\ marilani@unoeste.br
}

\section{RESUMO}

O autismo é um transtorno global que limita o indivíduo à interação social, uma vez que apresenta muita dificuldade na linguagem. O objetivo deste estudo foi mostrar as múltiplas possibilidades comunicacionais com os autistas, entender melhor seu universo e como com comunicação adequada eles podem ser bem aproveitados no ambiente organizacional. A metodologia empregada foram entrevistas com especialistas, pesquisas em livros teóricos específicos no assunto, reportagens em mídias digitais e artigos na internet. Os resultados foram as descobertas de que com as possibilidades comunicativas acertadas, o quanto a tal competência pode se tornar além de produtiva, competitiva no mercado. Conclui-se que é possível aprender muito com os autistas, mas que a comunicação com eles, pode ser o elemento chave, ou um entrave.

Palavras-chave: Multifaces Comunicacionais - autistas - ambiente organizacional.

\section{THE MULTIFACETED COMMUNICATIONAL WITH AUTISTIC IN ORGANIZATIONAL ENVIRONMENT}

\begin{abstract}
Autism is a global disorder that make the individual witchlimitations as social interaction, difficulty in language. The objective of this study was to show the multiple communication possibilities with autistic and better understand their universe. The methodology consisted of research in specialized books on the subject, reports in digitas media. The results were the discovery of how their power of them can recompensest the most productive and competitive organizations in the market. With all conclude that we can learn many with autism, to be objective, true, have persiste.
\end{abstract}

Keywords: Multifaceted communicational - autistic - organizational environment. 
INTRODUÇÃO

O Autismo é um transtorno Global que coloca o indivíduo em limitações na interação social e dificuldade na linguagem. Pode manifestar-se antes dos 3 anos de idade e se prolongar por toda a vida. Foram descritos e explicados pormenorizadamente pela primeira vez em 1943, onze casos pelo Dr. Leo Kanner em seu histórico artigo escrito originalmente em inglês "Distúrbio Autístico do Contato Afetivo".

Em 1944, Hans Asperger, um médico austríaco formado na Universidade de Viena, escreve outro artigo "Psicopatologia Autística da Infância", descrevendo comportamentos de crianças bastante semelhantes às descritas por Kanner. Ao contrário do artigo de Kanner, o de Asperger levou muitos anos para ser amplamente lido. Hoje em dia, atribuem-se tanto a Kanner como a Asperger as pesquisas realizadas sobre o autismo, embora cada um deles encontrem-se associados a distúrbios ligeiramente diferentes.

O autismo diferencia-se do retardo mental, porque enquanto no primeiro a criança apresente um desenvolvimento defasado, no autismo o perfil de desenvolvimento é regular podendo alcançar desafiadoramente a irregularidade, deixando os pais e profissionais, perplexos.

O objetivo deste trabalho é revelar como os autistas podem contribuir positivamente alcançando ótimos resultados para as organizações com comunicação precisa e eficaz a eles dirigida.

Desta forma, pretende-se revelar o resultado positivo que se pode alcançar com as possibilidades comunicacionais com os autistas no ambiente organizacional.

\section{METODOLOGIA}

Após muitas pesquisas, entrevistas e leituras realizadas, verificou-se que vários são os níveis de autismo que se pode detectar nos portadores desta síndrome. Há casos bastante acentuados. Por ser uma psicopatologia não tão amplamente divulgada e conhecida, o diagnóstico de crianças portadoras de autismo vêm crescendo e sendo identificados em idades cada vez mais precoces. O que se pode entender é que, junto à beleza de uma criança autista, sente-se a patologia como um problema multifacetado.

Conhecer profundamente um autista traz um aprendizado especial, uma vez que merece ser acolhido cuidado e estimulado ao desenvolvimento. Ele sente, olha e percebe o mundo de maneira bastante diferente dos demais. Para que a sociedade avance na inclusão, é necessário mergulhar neste universo particular para melhor entendê-lo. 


\section{RESULTADOS}

Depois de entrevistas com especialistas da área, pesquisas e leituras variadas, constatou-se que o Autismo é uma síndrome definida por estudiosos cientistas como alterações presentes desde idade muito precoce em algumas crianças; diferencial qualitativo na comunicação, dificuldade na interação social e no uso da imaginação. Por conta da dificuldade de comunicação, algumas necessidades e vontades não são atendidas, trazendo como consequência a raiva e frustação. A capacidade de se comunicar seja qual for a maneira, é fundamental.

Algumas crianças com autismo podem ter um excelente desenvolvimento da linguagem falada, assim como a ausência de fala nos primeiros anos de vida. Na maioria dos casos, é o fator que mais preocupa os pais, motivando-os a procurar ajuda. São entendidas como pessoas que não têm sentimentos. $\mathrm{O}$ que realmente acontece é que têm dificuldade em expressar seus afetos e o fazem de maneira inadequada, não por falta de sentimentos, mas por que a área do cérebro destinada aos sentimentos, não se conecta corretamente com a área onde os fatos são expressos. Isso faz com que eles tenham sentimentos verdadeiros e profundos, mas não consigam expressá-los tão facilmente.

Já com relação à disfunção social, percebe-se a dificuldade na interação social, uma vez que não conseguem estabelecer contato visual direto, pois não mostram um presente novo, e também não fazem questão de se engajar em atividades em grupo.

Para complicar um pouco mais os aspectos envoltos na comunicabilidade, apresentam acentuada dificuldade no desenvolvimento da linguagem. Os portadores desta psicopatologia que não apresentam prejuízos significativos na fala, têm dificuldade em iniciar, manter ou terminar uma conversa.

No que tange às disfunções comportamentais, apresentam interesses restritos, como por exemplo, o conhecimento profundo sobre um determinado assunto. Sempre são muito detalhistas, apegados à rotina, e voltados ao pensamento concreto. Possuem grande dificuldade em entender o sentido conotado das palavras ou das expressões frásicas. Possuem acentuada dificuldade de coordenação motora fina, como por exemplo, para recortar, pintar dentro dos espaços, escrever etc.

\section{DISCUSSÃO}

O autista sofre muito pelo fato das pessoas não entendem o seu jeito de se comunicar e isolam-se, para não sofrerem a rejeição. São inúmeras dificuldades, mas algo extraordinário ocorre com algumas pessoas que são portadoras desta síndrome. Podem sentar-se num piano e 
tocar uma melodia sem nunca ter frequentado escola de música; fazer cálculos matemáticos como se fossem os maiores gênios.

Certas características típicas do autismo, como a obsessão por assuntos específicos, a atenção aos detalhes, o hiper foco e a capacidade de pesquisar assuntos beirando à exaustão, fazem com que algumas pessoas do espectro autista sejam magníficas. Esse funcionamento mental propicia um hiperfuncionamento em áreas específicas do cérebro, em detrimentos de outras. Pesquisas revelam que cerca de $10 \%$ das pessoas com autismo são brilhantes em determinadas tarefas. Essas potencialidades espetaculares estão relacionadas às áreas de memória, cálculos matemáticos, cálculos de calendários, desenhos, artes plásticas, música, literatura e outras de conhecimento gerais. Embora não se possa afirmar, grandes personalidades do passado apresentavam características semelhantes ao do espectro autista, como: Leonardo da Vinci; Isaac Newton e Albert Einstein.

Características marcantes dos autistas podem ser fonte de exemplos para a sociedade, dentre elas, está a sinceridade, a ingenuidade e o comprometimento. Pessoas com espectro autista nunca fingirão amor; não dirão palavras amorosas sem que elas signifiquem exatamente 0 que estão sentindo. São totalmente do bem e jamais manipulariam os outros. Quando são inadequados, o fazem sem querer. Adoram animais.

No Brasil, há vários exemplos de pessoas que venceram as barreiras do autismo e se destacaram em diversas áreas de atuação, seus talentos foram despertados e direcionados corretamente, desenvolveram habilidades sociais, construíram amizades e atuam profissionalmente.

Quando se tenta o enquadramento destes indivíduos nos moldes da "normalidade", escapam-se as devidas oportunidades a possíveis gênios que podem mudar o curso da história da humanidade. Mas a genialidade não é suficiente. É preciso proporcionar caminhos que lhes possibilitem exercer suas reais potencialidades.

As empresas do setor de tecnologia da informação descobriram um enorme potencial nos autistas. O fabricante alemão para empresa SAP decidiu em maio de 2013 empregar nos próximos anos, centenas de autistas para formá-los em testes de software e programação, e em setembro do mesmo ano, começou a seleção na cidade alemã de Walldof. Já de início selecionou oito autistas para serem treinados, e começaram a trabalhar em janeiro 2014.

Silva (2012, p. 244) referenda que:

Até alguns anos atrás, as pessoas com autismo eram excluídas do mercado de trabalho por suas dificuldades, e também além de não serem entendidas não eram percebidas com clareza suas dificuldades de interação [...] Hoje em dia 
observamos que pode ocorrer exatamente o contrário e elas serem até requeridas por suas habilidades.

Silva em razão ao mencionar que os autistas eram excluídos do mercado de trabalho e sofriam a exclusão nitidamente. Hoje, percebe-se que eles se destacam pela excepcional habilidade de buscar e reconhecer erros, porque são pessoas extremamente perfeccionistas, detalhistas e capazes de ficar concentrados durante muitas horas. Eles têm habilidades lógicas e analíticas muito desenvolvidas, além de serem sérios e pouca ou nenhuma tolerância aos erros.

Esta empresa em 2011 havia começado um projeto similar na Índia, onde trabalharam com os autistas. Comprovaram que eles no trabalho com a tecnologia de informação estabelecem uma perfeita comunhão, uma vez que os portadores desta psicopatologia têm dificuldade de relacionamento interpessoal.

A Sancialisterne, fundada por Thorkel Sonne, pai de uma criança autista, oferece consultores em tecnologia da informação que tem diagnóstico no espectro do autismo ou similar. Entre os clientes de Spacialistrne estão Microsoft, Siemens, a empresa Sueca de serviços financeiros, etc. A empresa berlinense Auticon é a primeira na Alemanha a empregar exclusivamente autistas como consultores no setor de tecnologia da informação. Principalmente as empresa de tecnologia, têm procurado empregar pessoas com autismo para certas funções, não como uma iniciativa de caridade, mas por crer na competência deles para determinadas tarefas.

Os autistas promovem uma perspectiva diferente no local de trabalho, contribuindo largamente para a eficiência e a criatividade. Eles têm a natureza muito estruturada e apreciam resultados precisos, e não compreendem a simbologia figurada que recobrem as palavras. É Preciso olhar para esses pontos fortes e fracos e perceber o perfil para encaixá-los onde eles poderiam contribuir mais positivamente, agregando valor e resultados às organizações. Pessoas com esta síndrome podem se sobressair numa descrição passo a passo, sem omitir detalhes que outros podem deixar escapar. É imprescindível que no momento de seleção o entrevistador reconheça e esteja preparado para identificar tal potencial, pois eles geralmente não conseguirão ter bom desempenho verbal, oscilando entre a gagueira e na dificuldade com as palavras.

Aproveitar as habilidades únicas de pessoas no espectro autista tem o potencial de fortalecer os negócios, tornando-os mais competitivos. Com a melhor compressão sobre a síndrome, eles têm deixado a clausura do espaço privado e ganhado o espaço público. Atualmente começam a ser discutidas as habilidades associadas e como isso pode ser aproveitado em diferentes profissões. Há uma primeira geração chegando ao mercado de trabalho, porque eles 
possuem boa memória, mente muito estruturada, paixão por detalhes, bom faro para encontrar erros e perseverança para atividades repetitivas.

Durante muito tempo o autismo foi encarado como uma deficiência intelectual, mas o que se percebe é que em apenas alguns casos foram comprovados com tais deficiências. Muitos deles têm o intelecto preservado, com inteligência superior à média, mas não conseguem interagir, visto que não sabem usar os canais normais de comunicação. Por terem dificuldades na interação direta, outros meios de comunicação devem ser priorizados, como a escrita, por exemplo, por isso a internet é uma ferramenta de supra importância. Observam-se melhores rendimentos de trabalho dos autistas quando são montadas rotinas bem estruturadas, com poucas variações e com carga horária não muito extensas.

\section{CONCLUSÃO}

O autismo é um transtorno global que faz com que o indivíduo tenha limitações na interação social, tanto quanto dificuldade na linguagem. Os que têm o espectro autista com sintomas leves, podem se desenvolver muito bem, uma vez que cada um desenvolve habilidades especiais como, cálculo, raciocínio lógico, artes musicais etc.

Durante muito tempo o autismo foi visto como uma deficiência intelectual, mas hoje são entendidos como aqueles que têm o seu intelecto preservado, e vários comprovados com inteligência superior à média. Por terem tantos talentos, as empresas, principalmente as de tecnologia, estão em busca destes profissionais, já que são muito detalhistas, concentram-se por muitas horas, e, tem reduzida tolerância aos erros, o que agrega grandes benefícios às empresas.

Para que se consiga um convívio salutar com os autistas, é preciso despir-se dos preconceitos e mudar a postura diante deles. Enxergá-los além das limitações, e das dificuldades comunicacionais, é descortinar um novo universo para um possível convívio social para aqueles que têm habilidades ímpares, e precisam apenas de oportunidade para serem vistos, ouvidos, sentidos e além de inseridos, valorizados no ambiente organizacional.

\section{REFERÊNCIAS}

Autismo e educação [recurso eletrônico]: reflexões e propostas de intervenção - Claudio Roberto Baptista, ... [et al.]. Dados eletrônicos: Porto Alegre Artmed, 2007.

CAVALCANTI, Ana Elizabeth. Autismo: Construção e Desconstruções. 3. Ed. São Paulo: Casa do Psicólogo, 2007.

MELLO, Ana Maria S. Ros de. Autismo: guia prático. 5.ed, São Paulo: CORDE, 2007. 
NOTBOHM, ELLEN, Dez Coisas que Toda Criança com Autismo Gostaria que Você Soubesse. Trad. Mirtes Pinheiro. Florianópolis: Inspirados pelo Autismo, 2014.

Silva, Ana Beatriz B. Mundo Singular: entenda o autismo. Rio de Janeiro: Objetiva, 2012. 